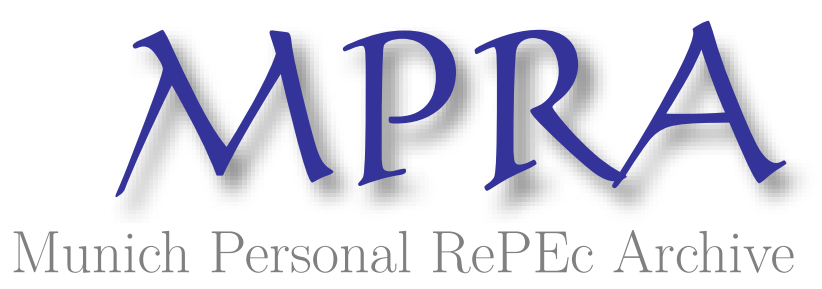

\title{
Understanding the Theories and Interventions of Motivation in Organization Development
}

Marczak, Emily and Yawson, Robert

University of Southern Maine, Quinnipiac University

18 May 2021

Online at https://mpra.ub.uni-muenchen.de/108001/

MPRA Paper No. 108001, posted 31 May 2021 08:55 UTC 


\title{
Understanding the Theories and Interventions of Motivation in Organization Development
}

\author{
Emily L Marczak \\ Leadership and Organization Studies, University of Southern Maine \\ emily.marczak@maine.edu
}

\author{
Robert M Yawson \\ School of Business, Quinnipiac University \\ https://orcid.org/0000-0001-6215-4345 \\ robert.yawson@qu.edu
}

In: Responsible Management: Opportunities and Challenges. Proceedings of 58th Annual Conference of the Eastern Academy of Management. Virtual, May 19 -21 https://doi.org/10.31124/advance.14610291.v1 


\begin{abstract}
This article reviews theories of motivation in the workplace, what these theories look like in the modern workplace, and interventions designed to increase individual and system-wide organizational motivation. We explored a wide range of theories, including the expectancy theory, Maslow's hierarchy, the motivation-hygiene theory, the equity theory, reward structures, cognitive evaluation theory, and feedback, to formulate conclusions about common organization development (OD) interventions that are meant to address the theories. Reviewed interventions include; organization structure design, achievement orientation, goal setting, job design, quality feedback, and empowerment programs. We followed a multidisciplinary integrated literature review approach to move beyond merely summarizing the literature but substantially contributing new and valuable knowledge to the fields of leadership and organization development. The research cements the need for understanding individuals' needs and goals, the value of quality feedback, rewarding positive behavior, leading with fairness, and allowing space for autonomy.
\end{abstract}

Keywords: motivation in the workplace, employee engagement, reward, needs hierarchy 


\section{Introduction}

Empirical evidence demonstrates that motivated employees mean better organizational performance and that motivated employees are more productive, engaged, efficient, and effective (Lee \& Raschke, 2016). Therefore, understanding how Organization Development (OD) can drive positive change toward employees' high motivation levels is a valuable investigation. To this end, Chanana and Sangeeta (2020) argue that "Organizations always remember that employees who are well engaged in an organization will lead to productivity in the place of work, and this generates a higher customer satisfaction and, absolutely, developments in sales and profit in the company" (p.1). In this paper, we will examine theories of motivation, OD interventions, how motivation is interconnected into organizational systems and structure, and where we anticipate the challenge of motivating employees to be headed in a post-COVID-19 world.

Organizations are naturally expected to create a healthy and positive relationship with their employees. Many organizations are trying to develop, maintain and improve their Human Resources (HR) strategies so that their employees become more motivated, for high performance, for both the short and the long-run success (Çetin \& Aşkun, 2018). Motivation works as a catalyzer for individual employees working for an organization to enhance their working performance or complete tasks much better than they usually do (Sekhar, Patwardhan, \& Singh, 2013). This is, however, not always the case, not because of a lack of trying. It is because employees have various competing needs that are driven by different motivators. "For example, some employees are motivated by rewards while others focus on achievement or security.” (Lee \& Raschke, 2016, p. 163). A Gallup survey finds that only 2 in 10 employees strongly agree that their performance is managed in a way that motivates them to do outstanding 
work (Wigert \& Harter, 2017). Therefore, an OD practitioner needs to understand what motivates employees to maximize organizational performance (Lee \& Raschke, 2016).

There are several definitions of employee motivation in the literature. Many researchers have attempted to develop a clear definition of motivation. Still, there seems to be no general agreement between researchers about how the term should be defined, although they mostly agree on its importance in organizations. What differs are the theories of motivation. Pinder, as noted by Meyer, Becker, and Vandenberghe (2004), defines employee motivation as, "A set of energetic forces that originates both within as well as beyond an individual's being, to initiate work-related behavior, and to determine its form, direction, intensity, and duration" (p.992). Work motivation is an employee's desire to make an effort that can be evoked internally by the enjoyment of work activities for their own sake or externally by a different outcome expected to follow from the successful pursuit of specific activities (Kauppila, 2018).

Employee motivation is critical to organizational performance because of the relationship with employee engagement. Chanana and Sangeeta (2020) claim, "Employee engagement is usually understood as an inner state of mind, that is, physically, emotionally, and mentally, that binds together the commitment, satisfaction, and work effort in an employee" (p.1). Hughes, Ginnett, and Curphy (2019) define employee engagement as, "A reward is any consequence that increases the likelihood that a particular behavior will be repeated" (p.350).

Lawler used the equation "Performance = Motivation x Ability" (Gallos, 2006, p. 635). The equation illustrates that motivation without skill will not equal a high level of performance and vice versa. Thus, if motivation is considered half of the ultimate impact for success, organizations need to understand how to provide their employees with those tools and training for skill alone. 
The objective of this review paper is two-fold: (1) to explore theories of motivation in the workplace, what these theories look like in the modern workplace and interventions that are designed to increase individual and system-wide organizational motivation, and (2) to articulate the progress made on understanding employee motivation from an OD perspective.

\section{Research Questions and Method of Inquiry}

We shaped our inquiry and review around the following questions:

1. What are the theories of motivation in the workplace, and how do these theories translate into practice in the contemporary workplace?

2. What are the common organization development (OD) inventions that are meant to address the motivational theories?

In addressing these questions, we explored a wide range of theories and concepts including; the expectancy theory, Maslow's hierarchy, the motivation-hygiene theory, the equity theory, reward structures, cognitive evaluation theory, and feedback, to formulate conclusions about common organization development (OD) interventions that are meant to address the theories. Reviewed interventions include; organization structure design, achievement orientation, goal setting, job design, quality feedback, and empowerment programs. We followed a multidisciplinary integrated literature review approach in our attempt at moving beyond merely summarizing the literature but substantially contributing new and valuable knowledge to the fields of leadership, human resource development, management, and organization development (Osafo \& Yawson, 2020; Snyder, 2019). The literature search covered a broad range of academic fields, including organization development, human resource development, organizational behavior, psychology, and other related social science fields. 


\section{Literature Review}

\section{Theories on Motivation}

Several major theories provide an understanding of employee motivation: motivationhygiene theory (Herzberg, Mausner, \& Snyderman, 1959), the hierarchy of needs (Maslow, 1943), expectancy theory, also referred to as the Valence Instrumentality Expectancy theory (Vroom, 1964), equity and justice theory (Adams, 1963), and, cognitive evaluation theory (Deci, 1971). Table 1 summarizes each motivation theory and its principles. We subsequently review these motivation theories and concepts.

\section{Table 1 - Employee motivation theories.}

\begin{tabular}{|c|c|c|}
\hline Theory & $\begin{array}{l}\text { Theorist \& } \\
\text { Reference }\end{array}$ & Main Motivating Principle \\
\hline Expectancy & Vroom (1964) & Work effort leads to performance and rewards. \\
\hline $\begin{array}{l}\text { Hierarchy of } \\
\text { needs }\end{array}$ & Maslow (1943) & $\begin{array}{l}\text { Hierarchy of needs: psychological, safety, social, ego, self- } \\
\text { actualizing. Work effort leads to performance and rewards. }\end{array}$ \\
\hline $\begin{array}{l}\text { Cognitive } \\
\text { evaluation }\end{array}$ & Deci $(1971)$ & $\begin{array}{l}\text { External elements affect intrinsic needs, intrinsic rewards, and } \\
\text { satisfaction. }\end{array}$ \\
\hline $\begin{array}{l}\text { Equity and } \\
\text { justice }\end{array}$ & Adams (1963) & $\begin{array}{l}\text { Employees strive for equity between themselves and other } \\
\text { employees. }\end{array}$ \\
\hline $\begin{array}{l}\text { Motivation- } \\
\text { hygiene theory }\end{array}$ & $\begin{array}{l}\text { (Herzberg et al., } \\
\text { 1959) }\end{array}$ & Categorizes motivation into two factors: motivators and hygienes \\
\hline
\end{tabular}

\section{The expectancy theory}

Vroom (1964) indicated that performance is a function of an individual's knowledge, skills, abilities, personality, and experiences. Edward E. Lawler in Gallos (2006) discussed the importance of motivation as it relates to performance. To understand why people act in the ways they do, Lawler also discussed the expectancy theory as a key to understanding motivation. "The expectancy theory argues that people are mostly rational decision-makers who think about their actions and act in ways that satisfy their needs and help them reach their goals" (Gallos, 2006, p. 
636). In other words, people are forward-looking, acting in ways that they see as most effective to attaining what they seek.

The expectancy theory postulates that motivation is a product of expectancy, instrumentality, and valence (Vroom, 1964). According to Vroom (1964), human actions and choices are driven by their desires and affection for certain outcomes, their belief that specific actions produce these outcomes, and that certain primary outcomes are associated with secondary outcomes (Vroom 1964). The expectancy theory alludes to the presence of reward within motivation. In the workplace, this equates with an individual working hard through a project that has value to an organization with the expectation of financial reward, praise, or promotion. The challenge here for organizations can be to figure out what individuals find rewarding. Everyone has different rewards that they seek; money, time off, status, travel, or flexibility. Organizations then need to find systems that fit into their corporate goals, values, and culture to meet individuals' needs.

\section{Maslow's hierarchy of needs}

A way to understand how needs and rewards progress through an individual's career is by looking at Maslow's hierarchy theory. According to Maslow (1943), employees have five levels of needs: physiological, safety, social, ego, and self-actualizing. Maslow (1943) argued that lower-level needs are first satisfied before the next higher level need would motivate employees.

The hierarchy shows that people's response to reward is based on where they fall on the hierarchy. "At the bottom, we all have fundamental physiological survival needs (food, water, shelter, security), followed by the need for social interaction, then respect from others, then selfesteem, and finally a need for personal growth and development" (Gallos, 2006, p. 637). This can mean that an individual's interests are within attaining basic needs or for someone further up 
the hierarchy, seeking personal development. What this leads to is that once a person meets a need, or a reward has been attained, then another need takes its place. This could be a financial interest or related to personal achievement. Thus, employers need to understand what motivates their employees while having an ongoing conversation to maintain motivation while further developing the individual.

Reward can also be referenced when considering the motivation relating to positive action within organizational change efforts. Gilley, Gilley, and McMillan (2009) discussed how to compliment strategic shifts with creating buy-in among employees:

Leaders secure desired results through a compensation and reward philosophy that recognizes employees for the right performance. Rewarding change efforts demonstrates the importance of and need for change, along with leaders' understanding that 'The things that get rewarded get done'(p.82).

In this case, reward is connected explicitly to positive behavior, vital to creating value for an individual. Thus, reward can positively reinforce the behaviors leaders want to be repeated instead of punishing the resistors.

\section{Cognitive evaluation theory (CET)}

Another theory explicitly related to reward, and motivation quality is the cognitive evaluation theory (CET). Cognitive evaluation theory is designed to explain the effects of external consequences on internal motivation (Deci, 1971). The theory challenges many of our standard workplace processes. In studying self-determination, Gagné and Deci (2005) found that external factors like; urgency, surveillance, and performance assessment reduced intrinsic motivation and other aspects of performance like creativity and flexibility. However, autonomy and feelings of competence led to higher levels of intrinsic motivation. Additionally, through 
vast experimentation, they found that rewards needed to be attached to specific accomplishments to increase intrinsic motivation. If the reward was contingent on success or given without direct connection to employee competence it was detrimental to employee motivation (Gagné \& Deci, 2005).

Understanding individual interests and values should also be a consideration for organizations and supervisors when establishing a reward structure. Culturally, there are implications with many types of rewards. Due to the difficulty in identifying precisely what motivates individuals, it is best to assume value is within a range of activities such as; supportive supervision, exciting work, high pay, job security, and family time (Gallos, 2006).

\section{Equity and justice theory}

A related theory to cognitive theory is the equity theory. Adams' (1963) equity and justice theory states that employees strive for equity between themselves and other employees. Wren (1995) defines it as "the theory that emphasizes the motivational importance to followers of fair treatment by their leaders. It assumes that people value fairness in leader-follower exchange relationships" (p. 330). This theory points back to consistent organizational strategy and values be related to human resources processes (Hughes et al., 2019). It also highlights the difference between equity and equality, meaning that treatment that motivates is not necessarily equal, but it is fair. This theory is easily accounted for in gender gaps in pay. Organizational ethics and justice shape employee behaviors and influence organizational performance (Y1ldiz, 2019).

Organizational justice is also connected closely to trust. As Lawler discusses in Gallos (2006), the perception of fairness relates to employee engagement. Leaders should be open with their decision-making processes, involve individuals in the decision-making process, create an 
environment for employees to trust decision-makers, employees should feel like the right people are in the discussion, and finally, that decisions can be safely challenged (Gallos, 2006). This analysis points to the value of the decision-making processes like search conferences and interventions that bring voices from the bottom up. Anderson (2020) describes that the goal of search conferences is "to encourage commitment to a common vision of the future and to develop energy to work on the action plans that will bring about that future in a highly participative environment" (p.302). It also speaks to the need for diversity within leadership. Without leadership representation of varied genders, races, gender identities, etc., individuals may not feel there is fairness in succession planning or that their views are represented.

\section{Motivation-hygiene theory}

Another theory that seeks to understand what motivates people at work was by Herzberg and called the motivation-hygiene theory. Herzberg's work categorized motivation into two factors: motivators and hygienes (Herzberg et al., 1959). Anderson (2020) notes that the theory differentiates between the aspects of the work environment that builds motivation and those that generally are detractors. Herzberg found that areas attributed to increased motivation are; an individual's feeling of performance quality, personal recognition, feedback, the individual's feelings of fit to the work, level of responsibility, and growth and advancement opportunities. In contrast, Herzberg worked with Mausner and Synderman to theorize on the areas that do not necessarily positively affect motivation when they are going well but can contribute to negative work experiences if an employee is dissatisfied (Anderson, 2020). These conditions include quality of supervision, relationships with others, salary, and corporate policies and processes. 


\section{Other employee motivation theories}

There are several other employee motivation theories, which we did not review in this paper, including; the Goal-setting theory, which posits that specific and difficult goals consistently lead to better performance than easy goals or no goals (Locke, 1996); Work design theory, which describes the five important job characteristics as skill variety, task identity, task significance, feedback, autonomy (Hackman \& Oldham, 1976); and the Reinforcement theory which maintains that managers should positively reinforce employee behaviors that lead to positive outcomes (Skinner, 1965). Aside from these 'traditional' employee theories, there are also contemporary ones drawn from cross-disciplinary research in fields like neuroscience, biology, and evolutionary psychology (Lee \& Raschke, 2016). A typical one being the human drives theory, which states that employees are guided by four basic emotional drives that are a product of common human evolutionary heritage: the drives to acquire, bond, comprehend and defend (Lawrence \& Nohria, 2001). While these other employee theories are essential for the OD intervention determinant goal of our study, they take their antecedents or are closely related to the ones we have discussed, and believe the core objectives are covered for the purposes our paper set to achieve.

\section{Organization Development Interventions and Implications for Practice}

From defining theories of motivation, there the question of how to turn these into OD interventions to increase workplace motivation and engagement. It should be noted that interventions can either be focused on the individual or a group. We will examine; the achievement orientation, goal setting, effective feedback job design, and empowerment programs.

The organizational design needs to be considered when looking at how motivation fits in 
systematically. Galbraith's "Star Model” illustrates the interconnected web of an organization and all of its parts needing strength to keep balance. Anderson (2020) reviews this model's components of strategy, structure, processes and lateral capability, reward systems, and people practices. Figure 1 illustrates the model. Employee motivation can be affected by each of these areas. Identifying imbalances and interventions to address those needs leads to greater performance. "Reward design and implementation plans should include tactics aligned with [or driving] desired strategy, structure, and culture. Organizations need to create innovative rewards to drive and maintain company performance above industry averages" (Heneman, Fisher, \& Dixon, 2001, p. 28).

Figure 1. Star Model

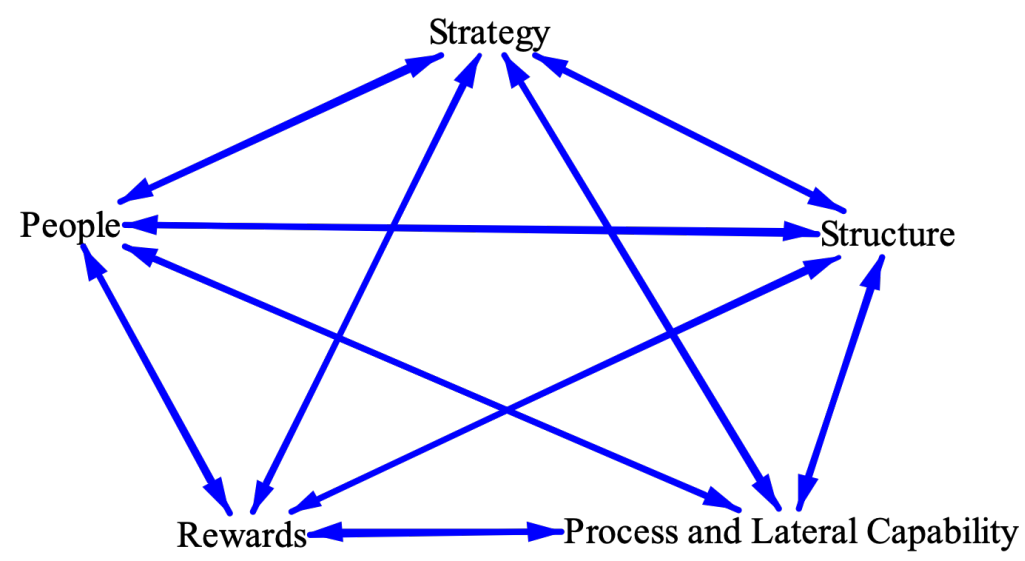

Galbraith Star Model illustrating organization structure. Redrawn from (Anderson, 2020)

The achievement orientation recognizes that each person has their own degree of energy and effort that they are willing to exert to succeed and thus have intrinsic motivation. Hughes et al. (2019) describe McClelland's view that some individuals have a high need for achievement. They seek tasks with challenges and opportunities for feedback. These are the employees who thrive with stretch tasks that give growth opportunities provided they have the knowledge that success is attainable. Organizations can tap into the energy of these individuals by identifying 
them through internal promotions or hiring processes. There is value in keeping high achievers motivated and tying them into other interconnected management interventions like job and task clarity.

An integral part of the organizational approach to motivation is goal setting. "The most powerful determinants of task behaviors. Goals direct attention, mobilize effort, help people develop strategies for achievement, and help people continue exerting effort until goals are reached" (Hughes et al., 2019, pg. 346). Locke and Latham (2002) found that goals can affect performance in four ways:

1. They direct attention and effort toward goal-relevant activities and away from goalirrelevant activities

2. Have an energizing function. High goals lead to more significant effort than low goals

3. Affect persistence. When participants are allowed to control the time they spend on a task, hard goals prolong effort

4. Affect action indirectly by leading to the arousal, discovery, and/or use of task-relevant knowledge and strategies.

We have found goal setting to be a well-integrated part of annual evaluation programs, which have incorporated this theory. To write individual goals that are more likely to reach desired outcomes, Locke and Latham (2002) found that essential aspects need to be accounted for, for goals to be motivating, valuable, and completed successfully. Hughes et al. (2019) explain that goals need to be specific, measurably difficult, have the employee's commitment, and coupled with feedback.

Connecting effective feedback into management processes is another way to impact motivation. Giving and receiving feedback can be challenging efforts. However, when done well, 
feedback cannot only increase performance but motivation. "For change to occur based on feedback, the feedback itself and the process must create energy"(Anderson, 2020, p. 189). OD practitioners must ensure that feedback is given in a way where the energy is being directed at the appropriate behavior and as an area for growth instead of punishment. "If the information is not seen as relevant, specific, or sufficient, for example, the client will resist it" (Anderson, 2020, p. 189).

Anderson (2020) also points to the value of data in presenting feedback. Being specific gives the employee the ability to have better clarity around issues or achievements (feedback can be positive as well). Feedback should be framed as opportunities for growth. If the feedback is positive, there should be opportunities to repeat the behavior. If the feedback is challenging, then learning goals can be set. "The feedback should be framed as unfinalized, that is, this discussion of the data gathering is not permanent state or condition" (Anderson, 2020, p. 189). Mentoring programs can be a valuable way for organizations to connect feedback with developing organizational knowledge and navigating an upward path for employees. Ultimately, feedback is a starting place for dialogue.

Pee and Lee (2015) studied the job characteristics that could affect motivation, precisely motivation to share knowledge online. The study referred to the five core job characteristics using the Hackman and Oldham model of workgroup effectiveness. The job design model suggests that job characteristics can influence various work outcomes such as work quality, job satisfaction, absence from work, and turnover. The five core job characteristics are skill variety, task identity, job autonomy, task feedback, and task significance (Pee \& Lee, 2015). In other words, an increase in motivation can come from jobs having greater variety in task type, the ability for an individual to participate in a task from the beginning and see it through to 
completion, autonomy for an employee in how and when tasks are completed, quality feedback on employee's work and finally that the tasks have an impact with the organization and/or other people (Pee \& Lee, 2015).

Clearly defining roles within teams and organizations can alleviate several challenges that can occur in the workplace, ultimately affecting employee motivation. Anderson (2020) points to several role-related problems that were identified by Adair. Some of these include (Anderson, 2020, p. 271):

- Role conflict - where one team member or multiple team members hold two mutually incompatible roles.

- Role incompatibility - when "there are incompatible expectations about a given role."

- Role overload - "when a person has too many roles to fulfill."

- Role underlay- when "a role is not fully developed with enough significant work or responsibilities."

- Role ambiguity - when "the role owner or team members are unclear about the responsibilities of a given role."

Clear job descriptions are an entry point to solving these challenges. Anderson (2020) describes the "role negotiation exercise" and "responsibility charting," which are designed to help teams alleviate the role issues. The role negotiation exercise, according to Anderson (2020), is reasonably straightforward. However, it allows team members to negotiate in a highly participative exercise their job responsibilities, preferences, and deliverables among themselves without being directed by a leader. Similarly, responsibility charting provides a space and process for teams to define who is responsible for what. The intention is to reduce conflict and create efficiencies (Anderson, 2020). 
Empowerment has become a buzz word in organizations. For most employees, empowerment has been connected to being trusted to do their best work, with the organization's goals and values in mind, but given the autonomy to drive projects in ways they feel are useful. According to Hughes et al. (2019), leaders struggle to define empowerment as whether it is driven top-down or bottom-up. In the opinion of Hughes et al. (2019), there are two critical components of empowerment. First, leaders need to distribute decision-making responsibility down to the lowest level of the organization possible. Secondly, employees need to be given the tools of skill development and organizational knowledge to make successful decisions. These two components recognize that lower-level employees often understand the organization's issues better because of their contact with the product and the importance of setting staff up to succeed with development tools to feel supported. In discussing a study that examined management style success for highly creative professionals, Gilley et al. (2009) showed that value in management empowered employees:

Specifically, $23 \%$ of respondents indicated that having freedom, flexibility, and resources was a significant motivator, while $25 \%$ indicated that the most important motivator was the time provided by their management [e.g., long stretches of time to focus on solving complex problem] (Gilley et al., 2009, p.81).

Hughes et al. (2019) find that empowered employees are more likely to be self-determined, have a sense of meaning in their work, are highly competent, have high levels of influence, and are more motivated in their positions.

In describing team interventions, Anderson (2020) discusses how organizations can integrate self-directed work teams (empowered teams). Organizations in this case need to direct decision- making power to lower-level staff and teams. This, however, does not mean they are 
not without oversight. "Self-directed teams have a wide variety of responsibilities, from goal setting, organizing work processes and schedules, and sorting out files and responsibilities to monitoring results and taking action when results don't meet requirements" (Anderson, 2020, p. 256). Because of their autonomy, these team members' buy-into the goals and processes, thus increasing motivation to execute. Anderson (2020) posits that this type of change to a work environment does require a shift in thinking. Employees are not able to turn unwanted power back to their managers. The responsibility and ownership firmly sit within the team. Shifting to this type of model, as with any change, requires the tools and support that set those employees up for success. Otherwise, old processes will return. Support is also needed to change the role of the supervisors. "Managers must shift from 'paternalistic' behaviors of monitoring and supervision to acting as a coach or mentor to the team" (Anderson, 2020, p.246).

\section{Conclusion}

The COVID-19 pandemic has forced the adoption of new ways of working, which directly impact employee motivation (Yawson, 2020). Organizations must reimagine their work and offices' role in creating safe, productive, and enjoyable jobs and lives for employees. Many employees are working from home, are struggling with a lack of childcare, the need to homeschool, and/or the effects of isolation. Companies are implementing hiring freezes, furloughing, and laying off employees. OD practitioners could play a vital role in managing a workplace that has changed and will continue to change over the long-term. Their knowledge is critical for organizational change that will increase or maintain previous levels of motivation during a time of high ambiguity. Robison (2009), in a discussion on management during turbulent times, gave suggestions for keeping employees motivated. Some of those include; being transparent with your employees about what is expected of them, making sure they have 
the right equipment, training, and tools to meet expectations, providing recognition for successes, letting your employees know that you care about them and their wellbeing, and finally discussing career development opportunities. Similarly, Talukar (2020) suggests five tips for maintaining or improving employee engagement, specifically during the COVID-19 pandemic, some more specific to newly created virtual teams. The recommendations include; creating a more robust communication plan for your remote teams, making sure to give employees instant appreciation, increasing flexibility, providing a virtual community with all your employees, and hosting online team building activities" (para. 10-19).

Ultimately, OD practitioners are likely to find intensified versions of their work. A disruption of this scale brought about by the pandemic is creating a sporadic shift in individuals' proclivities and expectations as citizens, employees, and consumers (Yawson, 2020). Our way of life, how we work, and how we use technology will be impacted significantly, and these create new challenges for OD theory, research, and practice (Yawson, 2020). Organizations may have smaller budgets, increased urgency, and more stretched and stressed employees. Bringing interventions back to OD's roots, thus seeing employees as whole persons, valuing diversity, bringing up challenges and solutions from the bottom-up and ensuring that people feel connected to the organization and their work will have value in the coming months and years.

We have explored a wide range of theories, including; the expectancy theory, Maslow's hierarchy, the motivation-hygiene theory, the equity theory, reward structures, and cognitive evaluation theory, to formulate conclusions about common organization development interventions that are meant to address the theories and their impact for practice. 
SYSTEMATIC REVIEWS OF HRD RESEARCH

\section{References}

Adams, J. S. (1963). Towards an understanding of inequity. The Journal of Abnormal and Social Psychology, 67(5), 422-436. https://doi.org/10.1037/h0040968

Anderson, D. L. (2020). Organization Development: The Process of Leading Organizational Change (5th ed.). Thousand Oaks, CA: Sage Publications Inc.,.

Çetin, F., \& Aşkun, D. (2018). The effect of occupational self-efficacy on work performance through intrinsic work motivation. Management Research Review, 41(2), 186-201. https://doi.org/10.1108/MRR-03-2017-0062

Chanana, N., \& Sangeeta. (2020). Employee engagement practices during COVID-19 lockdown. Journal of Public Affairs, (August). https://doi.org/10.1002/pa.2508

Deci, E. L. (1971). Effects of externally mediated rewards on intrinsic motivation. Journal of Personality and Social Psychology, 18(1), 105-115. https://doi.org/10.1037/h0030644

Gagné, M., \& Deci, E. L. (2005). Self-determination theory and work motivation. Journal of Organizational Behavior, 26(4), 331-362. https://doi.org/10.1002/job.322

Gallos, J. V. (2006). Organization Development. A Jossey-Bass Reader. (J. V. Gallos, Ed.), The Jossey-Bass business \& management series. San Francisco, CA: Jossey-Bass. A Wiley Imprint.

Gilley, A., Gilley, J. W., \& McMillan, H. S. (2009). Organizational change: Motivation, communication, and leadership effectiveness. Performance Improvement Quarterly, 21(4), 75-94. https://doi.org/10.1002/piq.20039

Hackman, J. R., \& Oldham, G. R. (1976). Motivation through the design of work: test of a theory. Organizational Behavior and Human Performance, 16(2), 250-279. https://doi.org/10.1016/0030-5073(76)90016-7 
SYSTEMATIC REVIEWS OF HRD RESEARCH

Heneman, R. L., Fisher, M. M., \& Dixon, K. E. (2001). Reward and Organizational Systems Alignment: An Expert System. Compensation \& Benefits Review, 33(6), 18-29. https://doi.org/10.1177/08863680122098694

Herzberg, F., Mausner, B., \& Snyderman, B. B. (1959). The motivation to work. New York, NY: John Wiley \& Sons Inc.

Hughes, R., Ginnett, R., \& Curphy, G. (2019). Leadership: Enhancing the Lessons of Experience (9th ed.). New York, NY: McGraw-Hill Education.

Kauppila, O. P. (2018). How does it feel and how does it look? The role of employee motivation in organizational learning type. Journal of Organizational Behavior, 39(8), 941-955. https://doi.org/10.1002/job.2270

Lawrence, P. R., \& Nohria, N. (2001). Driven: How Human Nature Shapes Our Choices. San Francisco, CA: Jossey-Bass.

Lee, M. T., \& Raschke, R. L. (2016). Understanding employee motivation and organizational performance: Arguments for a set-theoretic approach. Journal of Innovation and Knowledge, 1(3), 162-169. https://doi.org/10.1016/j.jik.2016.01.004

Locke, E. A. (1996). Motivation through conscious goal setting. Applied and Preventive Psychology, 5(2), 117-124. https://doi.org/10.1016/S0962-1849(96)80005-9

Locke, E. A., \& Latham, G. P. (2002). Building a practically useful theory of goal setting and task motivation: A 35-year odyssey. American Psychologist, 57(9), 705-717. https://doi.org/10.1037/0003-066X.57.9.705

Maslow, A. H. (1943). A theory of human motivation. Psychological Review, 50(4), 370-396. https://doi.org/10.1037/h0054346

Meyer, J. P., Becker, T. E., \& Vandenberghe, C. (2004). Employee Commitment and 
SYSTEMATIC REVIEWS OF HRD RESEARCH

Motivation: A Conceptual Analysis and Integrative Model. Journal of Applied Psychology, 89(6), 991-1007. https://doi.org/10.1037/0021-9010.89.6.991

Osafo, E., \& Yawson, R. M. (2020). Tempered radicalism as an approach to revisiting indigenous forms of critical human resource development. European Journal of Training and Development, ahead-of-p(ahead-of-print). https://doi.org/10.1108/EJTD-03-2020-0049

Pee, L. G., \& Lee, J. (2015). Intrinsically motivating employees 'online knowledge sharing: Understanding the effects of job design. International Journal of Information Management, 35(6), 679-690. https://doi.org/10.1016/j.ijinfomgt.2015.08.002

Robison, J. (2009). Building Engagement in This Economic Crisis. Retrieved January 1, 2021, from https://news.gallup.com/businessjournal/115213/building-engagement-economiccrisis.aspx? version=print

Sekhar, C., Patwardhan, M., \& Singh, R. K. (2013). A literature review on motivation. Global Business Perspectives, 1(4), 471-487. https://doi.org/10.1007/s40196-013-0028-1

Skinner, B. (1965). Science and Human Behavior (1st ed.). New York, NY: Free Press.

Snyder, H. (2019). Literature review as a research methodology: An overview and guidelines. Journal of Business Research, 104(March), 333-339.

https://doi.org/10.1016/j.jbusres.2019.07.039

Talukar, A. (2020). 5 Tips for Practicing Employee Engagement Amidst the COVID-19 Pandemic. Retrieved January 1, 2021, from https:/www.business2community.com/humanresources/5-tips-for-practicing-employee-engagement-amidst-the-covid-19-pandemic02300396

Vroom, V. H. (1964). Work and Motivation. New York, NY: Wiley.

Wigert, B. E. N., \& Harter, J. I. M. (2017). Re-engineering performance management. Gallup. 
SYSTEMATIC REVIEWS OF HRD RESEARCH

Washington DC: Gallup. Retrieved from https:/www.gallup.com/workplace/238064/reengineering-performance-management.aspx

Wren, T. (1995). The Leader's Companion: Insights on Leadership Through the Ages. New York, NY: The Free Press.

Yawson, R. (2020). Strategic flexibility analysis of HRD research and practice post COVID-19 pandemic. Human Resource Development International, 23(4), 406-417. https://doi.org/10.1080/13678868.2020.1779169

Yıldız, M. L. (2019). Etik Liderlik ve Örgütsel Adalet: İletişim Tatmininin Aracı Rolü. Turkish Journal of Business Ethics, 12(1), 75-112. https://doi.org/10.12711/tjbe.2019.12.1.0122 